\title{
QUEEN'S
UNIVERSITY
BELFAST
}

\section{Effect of reinforcement and heat treatment on elevated temperature sliding of electroless $\mathrm{Ni}-\mathrm{P} / \mathrm{SiC}$ composite coatings}

Franco, M., Sha, W., Aldic, G., Malinov, S., \& Çimenoğlu, H. (2016). Effect of reinforcement and heat treatment on elevated temperature sliding of electroless $\mathrm{Ni}-\mathrm{P} / \mathrm{SiC}$ composite coatings. Tribology International, 97, 265-271. https://doi.org/10.1016/j.triboint.2016.01.047

Published in:

Tribology International

Document Version:

Peer reviewed version

Queen's University Belfast - Research Portal:

Link to publication record in Queen's University Belfast Research Portal

Publisher rights

( 2016 Elsevier. This manuscript version is made available under the CC-BY-NC-ND 4.0 license http://creativecommons.org/licenses/by-ncnd/4.0/ which permits distribution and reproduction for non-commercial purposes, provided the author and source are cited.

\section{General rights}

Copyright for the publications made accessible via the Queen's University Belfast Research Portal is retained by the author(s) and / or other copyright owners and it is a condition of accessing these publications that users recognise and abide by the legal requirements associated with these rights.

Take down policy

The Research Portal is Queen's institutional repository that provides access to Queen's research output. Every effort has been made to ensure that content in the Research Portal does not infringe any person's rights, or applicable UK laws. If you discover content in the Research Portal that you believe breaches copyright or violates any law, please contact openaccess@qub.ac.uk. 
Effect of reinforcement and heat treatment on elevated temperature sliding of electroless Ni$\mathrm{P} / \mathrm{SiC}$ composite coatings

\section{Franco ${ }^{1}$, W. Sha ${ }^{1, *}$, G. Aldic ${ }^{2}$, S. Malinov ${ }^{3}$, H. Çimenoğlu ${ }^{2}$}

${ }^{1}$ School of Planning, Architecture and Civil Engineering, Queen's University Belfast, Belfast BT7 1NN, UK

${ }^{2}$ Department of Metallurgical and Materials Engineering, Istanbul Technical University, 34469 Maslak, Istanbul, Turkey

${ }^{3}$ School of Mechanical and Aerospace Engineering, Queen's University Belfast, Belfast BT7 $1 \mathrm{NN}, \mathrm{UK}$ 


\begin{abstract}
The investigation is focused on the wear behaviour at elevated test temperature of composite $\mathrm{Ni}-\mathrm{P} / \mathrm{SiC}$ deposit, with varying concentration of the reinforcing $\mathrm{SiC}$ particles. The phase evolution measured by X-ray diffraction suggests slight crystallisation during wear testing at $200{ }^{\circ} \mathrm{C}$. In coating without reinforcing particles, adhesive wear is accompanied by microcracks. The thermal heat generated and the cyclic loading could have induced subsurface microcracks. Owing to the effective matrix-ceramics system in composite coatings, fine grooves, abrasive polishing and uniform wearing are observed. Reinforcing particles in the matrix hinder microcrack formation and significantly reduce the wear rate. Triboxidation is confirmed from energy dispersive X-ray spectrometry.
\end{abstract}

Keywords: Electroless coating; Scanning electron microscopy; Metal matrix composite; High temperature 


\section{Introduction}

Owing to the demands for effective and high performing surface, electroless nickel deposit has been widely investigated and tailored based on the target applications [1-3]. Room temperature wear behaviour of electroless composite coatings without and with heat treatment has been studied by many investigators [4-9]. For applications involving elevated temperature during operation, understanding of the wear characteristics at elevated temperature testing condition is required.

Wear resistance of steel is improved when coated with $\mathrm{Ni}-\mathrm{P} / \mathrm{SiC}$ and heat treatment further increases the wear resistance, as reported by Staia et al. [10]. The tests were carried out at 100 ${ }^{\circ} \mathrm{C}$ and $300{ }^{\circ} \mathrm{C}$ using alumina ball as counter face. The wear mechanism is governed by the interaction between the ball and the coating. It is adhesive for coatings without heat treatment and abrasive for heat treated coatings. In another study involving elevated temperature wear testing at $550{ }^{\circ} \mathrm{C}$ of Ni-P coating sliding against AISI 52100 steel pins, the pre-heat treated coatings perform weaker in terms of wear rate as compared to coatings without heat treatment [11]. Wear morphology of the $400{ }^{\circ} \mathrm{C}$ heat treated coating shows finer grooves as compared to the coating pre-heat treated at higher temperature $\left(600{ }^{\circ} \mathrm{C}\right)$. Wang and Tung [12] studied various coatings on pistons, sliding against aluminium bore at $127^{\circ} \mathrm{C}$. The performance for $\mathrm{Ni}-\mathrm{P} / \mathrm{SiC}$ is ranked average with moderate wear and scuffing resistance as compared to other hard coatings. However, the effects of particles and the conditions of coatings are not clear. Recently, Ni-P/Cu coating and the effect of $\mathrm{Cu}$ on tribology behaviour at $60{ }^{\circ} \mathrm{C}$ test temperature were investigated by $\mathrm{Xu}$ et al. [13]. The wear loss is reduced with some spalling and slight furrow on the $\mathrm{Ni}-\mathrm{P} / \mathrm{Cu}$ coated cylinder as compared to uncoated cast iron having severe wear with furrows and corrosive pits. The tribo-film of $\mathrm{CuO}$ contributes to the enhancement in tribological performance. 
High temperature wear behaviour of Ni matrix based composite $\mathrm{Ni} / \mathrm{SiC}$ [14] and Ni-P/BN [15] coatings has also been reported. Although some investigations have been carried out on the elevated temperature surface property and wear characteristics of Ni-P/SiC deposit, studies on the effect of the incorporated particle concentration involving matrix-ceramics qualitative investigation are limited.

The motivation of the present study is to understand the surface performance at the elevated temperature test condition for the particle-reinforced composite coatings varying the concentration of the particles, a knowledge necessary for widening the industrial application involving sliding motion at elevated temperature environment. Studies on the phase composition, microstructure, and surface chemistry and roughness are also included. The emphasis is on the microstructural qualitative investigation and general trend rather than measuring the exact wear rate for each coating.

\section{Experimental details}

Aluminium alloy, LM24 (Al-8\%Si-3.5\%Cu, reference standard EN 1706 AC-46500) samples having dimension of $70 \mathrm{~mm} \times 35 \mathrm{~mm} \times 5 \mathrm{~mm}$ were coated with $\mathrm{Ni}-\mathrm{P} / \mathrm{SiC}$ with $\mathrm{SiC}(2-7 \mu \mathrm{m}$ particle size) as reinforcing particles. Medium phosphorus electroless nickel solution (NiKlad ELV 808MX) containing 5.4-6.3 g/l nickel metal, 27-33 g/l NaPO${ }_{2} \mathrm{H}_{2}$ and proprietary additives supplied by MacDermid was used as the base solution from which the composite coating was deposited varying the concentration of the reinforcing particles. The coatings under investigation in the present work are $\mathrm{A}(0 \mathrm{~g} / \mathrm{l} \mathrm{SiC}), \mathrm{B}(2 \mathrm{~g} / \mathrm{S} \mathrm{SiC}, \sim 14 \% \mathrm{SiC}$ in coating), $\mathrm{C}(6 \mathrm{~g} / 1 \mathrm{SiC}, \sim 24 \% \mathrm{SiC})$ and $\mathrm{F}(18 \mathrm{~g} / \mathrm{l} \mathrm{SiC}, \sim 42 \% \mathrm{SiC})$. The percentages of $\mathrm{SiC}$ in the coatings, here and where given elsewhere in the paper, are vol. \%. The pre-treatment and process parameters for the composite coatings were described elsewhere [16, 17]. 
Part of the samples were additionally heat treated in a furnace at $400{ }^{\circ} \mathrm{C}$ for $1 \mathrm{~h}$ and air cooled to ambient temperature. Cross section of the coatings was prepared metallographically. Scanning electron microscopes from Oxford Instruments and JEOL JSM 6500F having INCA $\mathrm{x}$-sight for energy dispersive X-ray (EDX) spectrometry were used to study the surface morphology and for elemental analysis. Phase composition of the composite coatings with and without heat treatment was analysed using PANalytical X-ray diffractometer applying CuK $\alpha$ radiation of wavelength $1.54 \AA$ and $\mathrm{X}$ 'Celerator detector, scanning at ambient temperature.

The wear behaviour was studied at $200{ }^{\circ} \mathrm{C}$ testing condition by dry sliding on the coatings without and with heat treatment using a ball-on-disk type wear tester, CSM high temperature tribometer (Switzerland). Test conditions and parameters are given in Table 1. The width and depth of wear track were measured using a profilometer (Dektak-6M, Veeco, USA). Triangular wear cross section was considered for volume loss calculation, consistent with previous work by the authors [16]. Fig. 1 shows an example of the profile scan data and the triangle used to approximate the profile and to calculate the wear rate. The use of a triangle is essentially using the trapezium rule of numerical integration, for the wear track cross sectional area. The cross section of every track was measured in six locations. Only one test was conducted for each coating as the emphasis of this research is on the general trend and qualitative investigation.

The wear rate is deduced by Eq. 1 and reported in $\mathrm{mm}^{3} \cdot \mathrm{N}^{-1} \mathrm{~m}^{-1}$ :

Specific wear rate $=\frac{v}{w l}$

where $v$ is the wear volume $\left(\mathrm{mm}^{3}\right), w$ is the load $(\mathrm{N})$ and $l$ is the sliding distance $(\mathrm{m})$. 
Roughness was measured by using a Rugosurf $10 \mathrm{G}$ roughness tester, following the standard ISO 4287:1997, on the unworn and worn surface transverse the wear track. The average at three different locations is reported. The probe was run over a distance of $4.8 \mathrm{~mm}$ on the test surface. The difference in the roughness values is expected to complement the wear results.

\section{Results and discussion}

\subsection{Coating structure and surface roughness}

Microscopy in cross section of the electroless nickel deposition (Fig. 2) shows the uniformity of the deposition and even distribution of the reinforcing particles, $\mathrm{SiC}$, in the nickelphosphorus matrix for the composite coating. The irregular micron size particles $(2-7 \mu \mathrm{m})$ are dispersed and enveloped in the matrix easily and densely even without the addition of surfactant. The deposition thickness of the composite Ni-P/SiC onto the aluminium alloy substrate is in the range of $25-30 \mu \mathrm{m}$.

Fig. 3 shows the surface roughness ( $\mathrm{Ra}$ ) of coatings A and $\mathrm{F}$ without and with heat-treatment. Measurements are performed on unworn coating and across the wear track. Worn surfaces of all the coatings exhibit higher roughness than the unworn surfaces. The roughness is contributed mainly from the wear track width and the depth when the probe scans across the track. A closer look indicates that the roughness values increase significantly after wearing for the coatings without particles (A) than the ones with particles $(F)$. The small difference in these values for coating $\mathrm{F}$ is attributed to the shallow material removal and homogeneous wear track.

\subsection{Wear characteristics and the particle effects}

Fig. 4 gives comparative wear rate of the coatings (A, B, C and F). The wear rate has similar order of magnitude $\left(10^{-5}-10^{-4} \mathrm{~mm}^{3} \cdot \mathrm{N}^{-1} \mathrm{~m}^{-1}\right)$ as literature reports (between $10^{-6}$ and $10^{-4}$ 
$\left.\mathrm{mm}^{3} \cdot \mathrm{N}^{-1} \mathrm{~m}^{-1}\right)[10,14,15]$. The wear rate decreases as the content of the particles increases. Heat treatment (pre-heat treated at $400{ }^{\circ} \mathrm{C}$ for $1 \mathrm{~h}$ ) further improves the wear resistance as compared to the without heat treatment condition for each coating. Interestingly, the composite coatings $\mathrm{B}(\sim 14 \% \mathrm{SiC}), \mathrm{C}(\sim 24 \% \mathrm{SiC})$ and $\mathrm{F}(\sim 42 \% \mathrm{SiC})$ [17] without heat treatment have better wear resistance than the coating without particles $(\mathrm{A})$ in heat treated state, which should be considered when judging the processing cost in terms of removing the need for thermal processing.

To further understand the role of particles and wear mechanism, the wear morphology and tracks are studied (Fig. 5). Plastic deformation is observed with parallel micro ploughing in all cases. However, Ni-P coating without heat treatment shows typical adhesive wear morphology (Fig. 5a) with more material removed due to the relatively softer coating as compared to heat treated and composite coatings. The formation of noticeable microcracks on the worn surface can be explained as a result of the shear stress transmitted to the sub-surface layer and the cyclic nature of load. The strain is accumulated with the formation of cracks and the presence of adhesive force results in higher roughness [15]. Detachment of sub-layer of coating owing to the adhesive wear agrees with the transfer of the coating material on the surface of the counter ball (Fig. 6a). The adhesive wear mechanism is in agreement with literature [10]. The coating without heat treatment is amorphous having low hardness, high ductility and weaker adhesion to substrate [11]. The microhardness of coating A without heat treatment is lower than composite coatings (B, C and F) [16]. The particles incorporated coating B (without heat treatment) in Fig. 5c exhibits fine parallel grooves and some characteristics of adhesive wear. The particle effect is not yet fully matured to harden the composite as a whole. After increasing the content of reinforcing SiC particles in the coating, the mechanism moves towards abrasive wear characterised by dense parallel micro scratches accompanied by reduction in the patches area as shown by the wear morphology of coatings 
$\mathrm{C}$ (Fig. 5e) and F (Fig. 5g). The abrasive wear is due to pulled out particles rolling over and acting as third body abrasion that results in the coatings being abraded along the ball sliding. The highest content of $\mathrm{SiC}$ in coating $\mathrm{F}$ leads to the densest micro grooves featured by abrasive polishing. The wear morphology appears to be the outcome of a homogeneous material system. The densely distributed particles have good bonding with the matrix that helps to enhance the mechanical properties and consequently reduces the wear effect uniformly. High magnification micrographs in Fig. 7 detail the micro-level behaviour of the particle-matrix combined system in the worn morphology for coating $\mathrm{F}$ (without heat treatment). In the matrix, the load bearing hard $\mathrm{SiC}$ particles are found to be pressed-in, which helps to reduce wear volume. The shape of particles can be seen in Fig. $2 b$. The particles do not have round surfaces, but are strongly faceted. It is believed that particles oriented with their largest facet parallel to the coating surface are more likely to get pressedin. On the other hand, particles with angular orientation are prone to participating in wear action [18]. However, minor movement of the particles which could be due to unfavourable orientation (elongated particles are located perpendicularly to the tribo-surface) is also visible. The wear scar of the counter body $\left(\mathrm{Al}_{2} \mathrm{O}_{3}\right.$ ball $)$ is smaller after testing of composite coating F (Fig. 6). This indicates that load carrying capacity of given tribocouple is higher.

Pre-heat treated coatings exhibit very uniform and fine scratches (Figs. 5b, 5d, 5f and 5h). The strong sharp grooves are the result of the pressure exerted by the counter body onto the hard surface. Coating $\mathrm{A}(0 \% \mathrm{SiC})$ in Fig. $5 \mathrm{~b}$ shows many deeper grooves in addition to the shallow and finer ones, which could be due to the action of the entrapped hard debris of wear. As the content of $\mathrm{SiC}$ increases [17], the wear morphology is smoother and the grooves are finer. Coating F ( 42\% SiC) having the highest content of SiC exhibits uniform worn surface with very fine and shallow abrasion. The high content of particles could have played a strong role supported by the hardened matrix to resist the contact pressure from sliding ball, leaving 
mild parallel scratches. The polished abrasive action for heat treated coatings was also reported by Aslanyan et al. [4] and Staia et al. [10], with stronger interaction between the matrix and the reinforcing particles. The microhardness of heat treated coatings is higher than coatings without heat treatment. Among pre-heat treated coatings, the trend follows in which particles free coating has the lowest microhardness and the maximum microhardness value is reached with a specific content of reinforcing particles beyond which no significant change is observed [16]. No direct measurements were carried out on adhesion and toughness of the coatings, but an indirect investigation has been reported [19].

The absence of microcracks and less material transfer in pre-heat treated state and after SiC inclusion can be correlated with the finding by Masoumi et al. [11] who described that only when optimum crystalline grain size is obtained will crack propagation through the material be suppressed, which helps to relax stress concentration before crack penetrates, resulting in the reduction of the wear volume. Microstructure changes upon heating. The ideal crystalline grain size is obtained from thermal processing at $400{ }^{\circ} \mathrm{C}$. In the present case, the embedding particles promote elimination and stoppage of microcracks [19]. Further, the synergistic effect of heat treatment and the reinforcing particles shows positive influence in crack elimination and stoppage. Composite coatings in pre-heat treated state show relatively well defined particle distribution post sliding with fine scratch lines attributed to the stabilised and rigid settlement of the particles in the hardened matrix. On the contrary, coatings without heat treatment do not show as distinct distribution, which could be due to slight movement of the particles in the soft amorphous matrix. The amount of pulled out or detached $\mathrm{SiC}$ could be slightly larger for the without heat treatment condition. The morphology agrees with the wear rate trend in Fig. 4.

\subsection{Cross section and chemical analyses}


Cross sectional observation of the wear scar (Fig. 8) firmly supports that the wear test is within the coating without the exposure of the base substrate. The particles free coating (A, Fig. 8a) exhibits wider and deeper wear scar as compared to the coating with particles (F, Fig. 8b). Shallow dent with smaller amount of material removal is the evidence of the effect of reinforcing particles resisting the pressure of the counterpart under normal load. The worn depth at the central region is calculated and found to be $14 \mu \mathrm{m}$ for the particles free coating and $4.8 \mu \mathrm{m}$ for the composite coating, which are in good agreement with the profilometer scanning giving depth averages of $13.4 \mu \mathrm{m}$ and $4.2 \mu \mathrm{m}$, respectively. The yellow lines in Fig. 8 show the size of contact, curved to illustrate the variation of stress and the wear depth. In the centre of the wear cross section, the stress is concentrated and maximum. A closer examination of the coating material underneath the track area reveals some microcracks developed in the particles free coating (Fig. 8c) with irregular wear on the top surface. Shallow microcracks are seen near the surface for composite coating F just about $2 \mu \mathrm{m}$ beneath the wear track, near to the stress concentrated region (typical example for abrasive microcracking) [20]. As discussed earlier, in the particles free coating, that shear stress transmitted to the sub-surface layer increases together with the cyclic nature of load results in the formation of a considerable number of cracks $[11,15]$. With the inclusion of particles in the matrix, any crack formed is suppressed to propagate. The mean free path for crack propagation is smaller as the probability to encounter particles is larger, thereby reducing the lengthening of microcracks [11]. The present study involves testing at elevated temperature on the thermally sensitive Ni-P coatings. In general, fracture toughness is higher for Ni-P without heat treatment but the property could be altered when testing at $200{ }^{\circ} \mathrm{C}$ resulting in deterioration in toughness. Literature $[21,22]$ suggests that, as the heat treatment temperature increases, fracture toughness decreases. So, the elevated test temperature could be detrimental to coatings without heat treatment causing cracking, particularly in coating without particles. 
After reinforcing, the combined effect of matrix and the particles at the testing temperature may have effectively reduced the amount of microcracks [19]. The plastic deformation on the wear surface is roughly via a grinding action by material mixture of varied sizes under the action of the shear force during sliding. There is both deformation (no loss of material) and grinding (causing loss of material). The top worn mixture of material which is a mechanically mixed layer [5] is primarily triboxidative as confirmed by the EDX chemical analysis shown in Fig. 9b. In Fig. 9a, the low oxygen peak in the spectrum from the unworn area far away from the track (distance between wear track and area of measurement at least $8 \mathrm{~mm}$ ) reveals that minimum oxidation takes place in the area far away from the track. The dissipation of the contact heat is not significant enough to cause oxidation, because of the too little frictional heat generated, high thermal conductivity of the substrate and the coating providing removal of heat, and the location of the measurement too far away.

\subsection{Phase structure post wear test}

The diffraction patterns (Fig. 10) show the effect of heat treatment and wear testing for coating $\mathrm{F}$. The comparison is an attempt to find possible phase changes during the operating elevated temperature test condition especially in the untreated coatings. The diffraction pattern for the coating without heat treatment after wear test changes to slightly sharper and narrower peak from amorphous state comparatively but without strong crystalline peaks. The elevated test temperature of $200{ }^{\circ} \mathrm{C}$ contributes to the slight evolution of phase to crystalline state. Initiation of microstructural change should be at $220-260{ }^{\circ} \mathrm{C}$ [1]. The XRD finding is also an indicative confirmation that the heat generated during the sliding friction of two bodies does not significantly dissipate to the whole coating thereby accumulation of heat to cause perfect crystalline phases is ruled out. The net coating temperature is lower than the phase transformation temperature (above $320^{\circ} \mathrm{C}$ ) [1]. Lekka et al. [14] reported that the microstructure of the area away from the wear track does not change greatly. 
Pre-heat treatment at $400{ }^{\circ} \mathrm{C}$ results in the expected strong crystalline phases indicated by sharp and well-defined peaks from cubic $\mathrm{Ni}$ and tetragonal $\mathrm{Ni}_{3} \mathrm{P}$. Evolution of nickel silicide phase as $\mathrm{NiSi}_{2}$ with its strongest peak observed at $2 \theta \approx 47^{\circ}$ is shown in pre-heat treated coating, which is consistent with the diffraction pattern after the normal heat treatment at 400 ${ }^{\circ} \mathrm{C}$ for $1 \mathrm{~h}$.

Several topics should be suitable for future research, but are outside the scope of the present paper. These include:

- higher magnification images to show particle-matrix interface and interaction

- EDX maps of the wear surfaces

- detailed wear mechanisms and observation of the failure modes, especially the cracks

- comparison of the friction and its evolution along the tests, to help understand the behaviour of the different coatings and the mechanisms

- calculation of the Hertzian contact stress.

\section{Conclusion}

(1) Phase transformation and change in microstructure due to frictional heating on the coatings are not profound post wear test at $200{ }^{\circ} \mathrm{C}$. However, onset of evolution of crystallisation is exhibited with slight change to sharper XRD peaks due to the test temperature and the minimal generated frictional heat.

(2) On reinforcing with particles, reduction of wear rate is observed as compared to the particles free coating. Heat treatment further increases the wear resistance due to the better bonding of the reinforcing particles and the matrix. Surface roughness measurement confirms the effectiveness of ceramics in composite coating.

(3) Particles free coating (without heat treatment) exhibits adhesive wear with microcracks having developed on the top surface as well as underneath the wear track 
due to applied mechanical and thermal stress. Incorporation of particles assists in load bearing and also facilitates interruption of microcrack propagation at sub-surface region. Abrasive wear and triboxidation occur in composite and heat treated coatings.

\section{Acknowledgements}

A studentship funding from Queen's University Belfast, technical assistance from Dr. Mark Russell, Stephen McFarland, Jim Knox and his team of Queen's University Belfast, and initiating project by Dr. Rajendran of B.S. Abdur Rahman University, India are acknowledged.

\section{References}

[1] J. Sudagar, J. Lian, W. Sha, Electroless nickel, alloy, composite and nano coatings - A critical review, J. Alloy. Compd. 571 (2013) 183-204.

[2] K.G. Keong, W. Sha, S. Malinov, Hardness evolution of electroless nickel-phosphorus deposits with thermal processing, Surf. Coat. Technol. 168 (2003) 263-274.

[3] J.N. Balaraju, T. Sankara Narayanan, S. Seshadri, Electroless Ni-P composite coatings, J. Appl. Electrochem. 33 (2003) 807-816.

[4] I.R. Aslanyan, J-P. Boninoc, J-P. Celis, Effect of reinforcing submicron SiC particles on the wear of electrolytic NiP coatings, Part 1. Uni-directional sliding, Surf. Coat. Technol. 200 (2006) 2909-2916.

[5] Y. Wu, H. Liu, B. Shen, L. Liu, W. Hu, The friction and wear of electroless Ni-P matrix with PTFE and/or SiC particles composite, Tribol. Inter. 39 (2006) 553-559. 
[6] A. Grosjean, M. Rezrazi, J. Takadoum, P. Berçot, Hardness, friction and wear characteristics of nickel-SiC electroless composite deposits, Surf. Coat. Technol. 137 (2001) 92-96.

[7] I. Apachitei, F.D. Tichelaar, J. Duszczyk, L. Katgerman, The effect of heat treatment on the structure and abrasive wear resistance of autocatalytic NiP and NiP-SiC coatings, Surf. Coat. Technol. 149 (2002) 263-278.

[8] M.H. Staia, E.S. Puchi Cabrera, A. Iost, A. Zairi, S. Belayer, A. Van Gorp, Tribological response of AA 2024-T3 aluminium alloy coated with a DLC duplex coating, Tribol. Inter. 85 (2015) 74-87.

[9] D. Gutsev, M. Antonov, I. Hussainova, A.Ya. Grigoriev, Effect of $\mathrm{SiO}_{2}$ and PTFE additives on dry sliding of NiP electroless coating, Tribol. Inter. 65 (2013) 295-302.

[10] M.H. Staia, A. Conzono, M.R. Cruz, A. Roman, J. Lesage, D. Chicot, G. Mesmacque, Wear behaviour of silicon carbide/electroless nickel composite coatings at high temperature, Surf. Eng. 18 (2002) 265-269.

[11] F. Masoumi, H.R. Ghasemi, A.A. Ziaei, D. Shahriari, Tribological characterization of electroless $\mathrm{Ni}-10 \% \mathrm{P}$ coatings at elevated test temperature under dry conditions, Int. J. Adv. Manuf. Technol. 62 (2012) 1063-1070.

[12] Y. Wang. S.C. Tung, Scuffing and wear behavior of aluminum piston skirt coatings against aluminum cylinder bore, Wear 225-229 (1999) 1100-1108.

[13] Y. Xu, X. Zheng, X. Hu, Y. Yin, T. Lei, Preparation of the electroless Ni-P and Ni-Cu-P coatings on engine cylinder and their tribological behaviours under bio-oil lubricated conditions, Surf. Coat. Technol. 258 (2014) 790-796. 
[14] M. Lekka, A. Lanzutti, A. Casagrande, C. de Leitenburg, P.L. Bonora, L. Fedrizzi, Room and high temperature wear behaviour of Ni matrix micro- and nano-SiC composite electrodeposits, Surf. Coat. Technol. 206 (2012) 3658-3665.

[15] O.A. León, M.H. Staia, H.E. Hintermann, High temperature wear of an electroless Ni-PBN (h) composite coating, Surf. Coat. Technol. 163-164 (2003) 578-584.

[16] M. Franco, W. Sha, S. Malinov, H. Liu, Micro-scale wear characteristics of electroless Ni-P/SiC composite coating under two different sliding conditions, Wear 317 (2014) 254264.

[17] M. Franco, W. Sha, S. Malinov, R. Rajendran, Phase composition, microstructure and microhardness of electroless nickel composite coating co-deposited with $\mathrm{SiC}$ on cast aluminium LM24 alloy substrate, Surf. Coat. Technol. 235 (2013) 755-763.

[18] I. Apachitei, F.D. Tichelaar, J. Duszczyk, L. Katgerman, The effect of heat treatment on the structure and abrasive wear resistance of autocatalytic NiP and NiP-SiC coatings, Surf. Coat. Technol. 149 (2002) 263-278.

[19] M. Franco, W. Sha, V. Tan, S. Malinov, Insight of the interface of electroless Ni-P/SiC composite coating on aluminium alloy, LM24, Mater. Des. 85 (2015) 248-255.

[20] J.H. Tylczak, Abrasive wear, In: Friction, Lubrication, and Wear Technology, ASM Handbook, Vol 18, ASM International, 1992, pp 184-190.

[21] Q.J. Zhou, J.Y. He, D.B. Sun, W.Y. Chu, L.J. Qiao, Deformation and fracture of nickel phosphorus coatings, Scripta Mater. 54 (2006) 603-608. 
[22] W. Sade, R.T. Proença, T.D. de Oliveira Moura, J.R.T. Branco, Electroless Ni-P

coatings: Preparation and evaluation of fracture toughness and scratch hardness, ISRN Mater.

Sci. 2011 (2011) 693046.

\section{List of figure captions}

Fig. 1. An example of profile scan data for particles free coating A without heat treatment and the triangle used to approximate the profile and to calculate the wear rate.

Fig. 2. Micrographs of cross section for (a) particles free coating A and (b) composite coating $\mathrm{F}(18 \mathrm{~g} / \mathrm{l} \mathrm{SiC})$.

Fig. 3. Roughness values for coatings A and $\mathrm{F}$ without and with heat treatment measured at unworn and worn areas. ("A-AD" = A without heat treatment, "A-HT" = A with heat treatment, "F-AD" = F without heat treatment, "F-HT" = F with heat treatment).

Fig. 4. Wear trend for coatings with different contents of $\mathrm{SiC}$ particles $(\mathrm{A}=0 \%, \mathrm{~B}=14 \%, \mathrm{C}$ $=24 \%$ and $\mathrm{F}=42 \% \mathrm{SiC})$.

Fig. 5. Optical images for (a) A without heat treatment, (b) A with heat treatment, (c) B without heat treatment, (d) B with heat treatment, (e) C without heat treatment, (f) C with heat treatment, (g) F without heat treatment, (h) F with heat treatment.

Fig. 6. Wear morphology on counter body after sliding on (a) particles free coating A, (b) composite coating F. Both coatings A and F are without heat treatment.

Fig. 7. Micrographs showing particle-matrix behaviour and worn morphology. Composite (F, $18 \mathrm{~g} / \mathrm{l} \mathrm{SiC}$ ) coating (without heat treatment).

Fig. 8. Cross section showing subsurface of the wear track for $(a, c)$ the particles free coating A and (b, d) composite coating F. Coatings A and F are without heat treatment. 
Fig. 9. EDX spectra showing difference in the size of the oxygen peak after wear testing, taken from (a) unworn and (b) worn areas for coating F without heat treatment.

Fig. 10. X-ray diffraction pattern for composite coating $\mathrm{F}$ without heat treatment $(18 \mathrm{~g} / \mathrm{l} \mathrm{SiC})$, post wear at $200{ }^{\circ} \mathrm{C}$ of coating $\mathrm{F}$ without heat treatment (AD), and post wear at $200{ }^{\circ} \mathrm{C}$ of coating F with heat treatment $(\mathrm{HT})\left(400{ }^{\circ} \mathrm{C}\right.$ for $\left.1 \mathrm{~h}\right)$. The patterns on wear tested coatings were collected from surface areas adjacent to but not including the wear tracks. 
Table 1. Wear test parameters

\begin{tabular}{ll}
\hline Parameter & Value \\
\hline Load & $2 \mathrm{~N}$ \\
Speed & $0.1 \mathrm{~m} / \mathrm{s}$ \\
Duration & $50 \mathrm{~min}$. \\
Sliding distance & $300 \mathrm{~m}$ \\
Ball radius & $6 \mathrm{~mm}$ (alumina Grade 10, S Series ISO 3290) \\
\hline
\end{tabular}




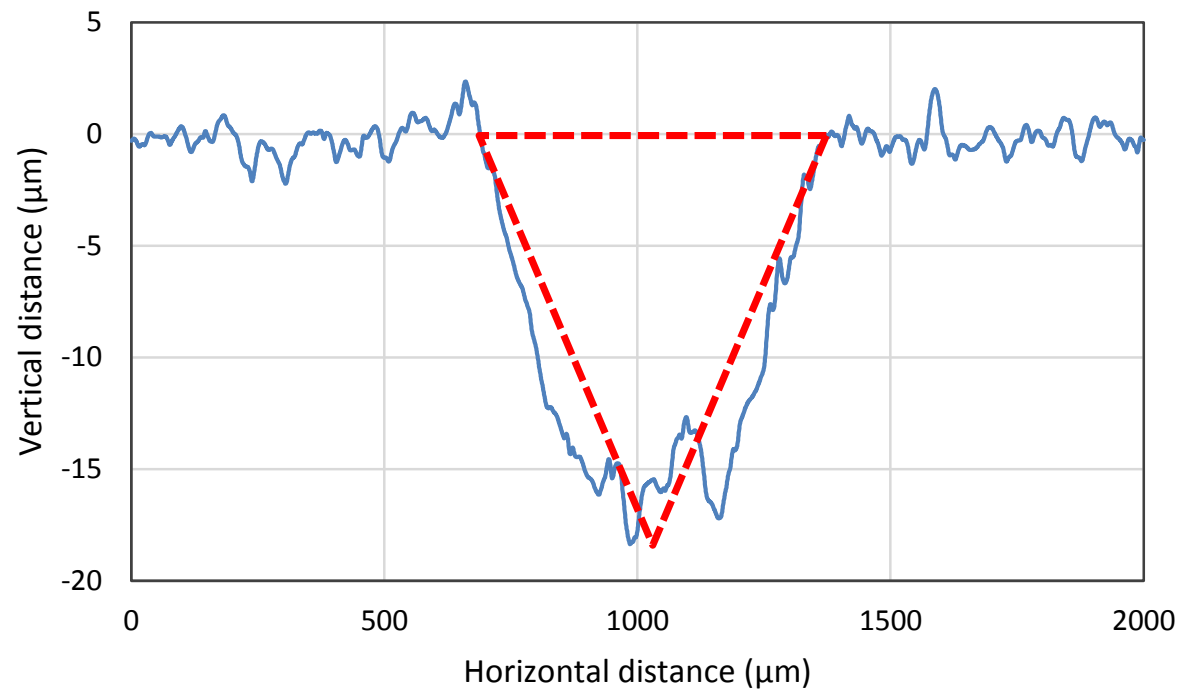

Fig. 1 

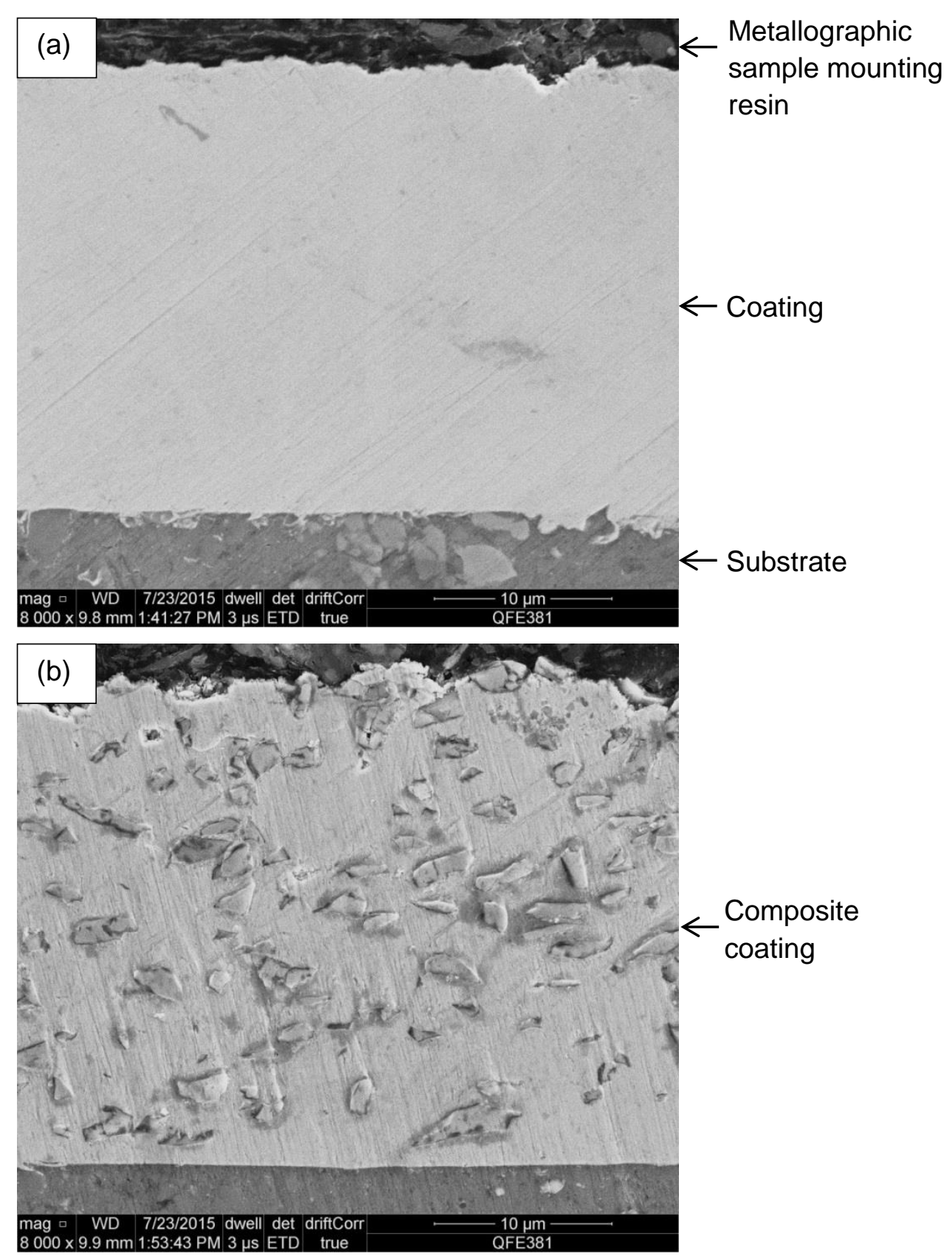

Fig. 2 


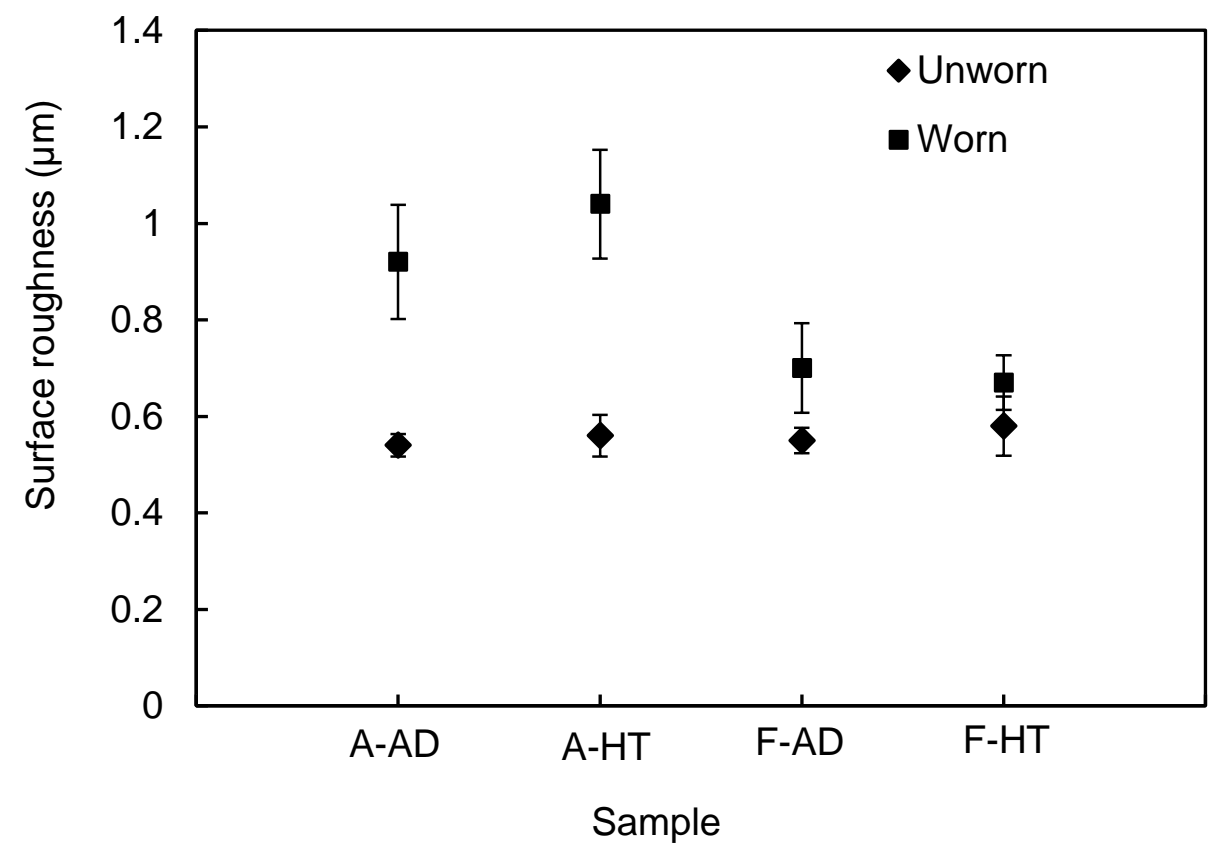

Fig. 3 


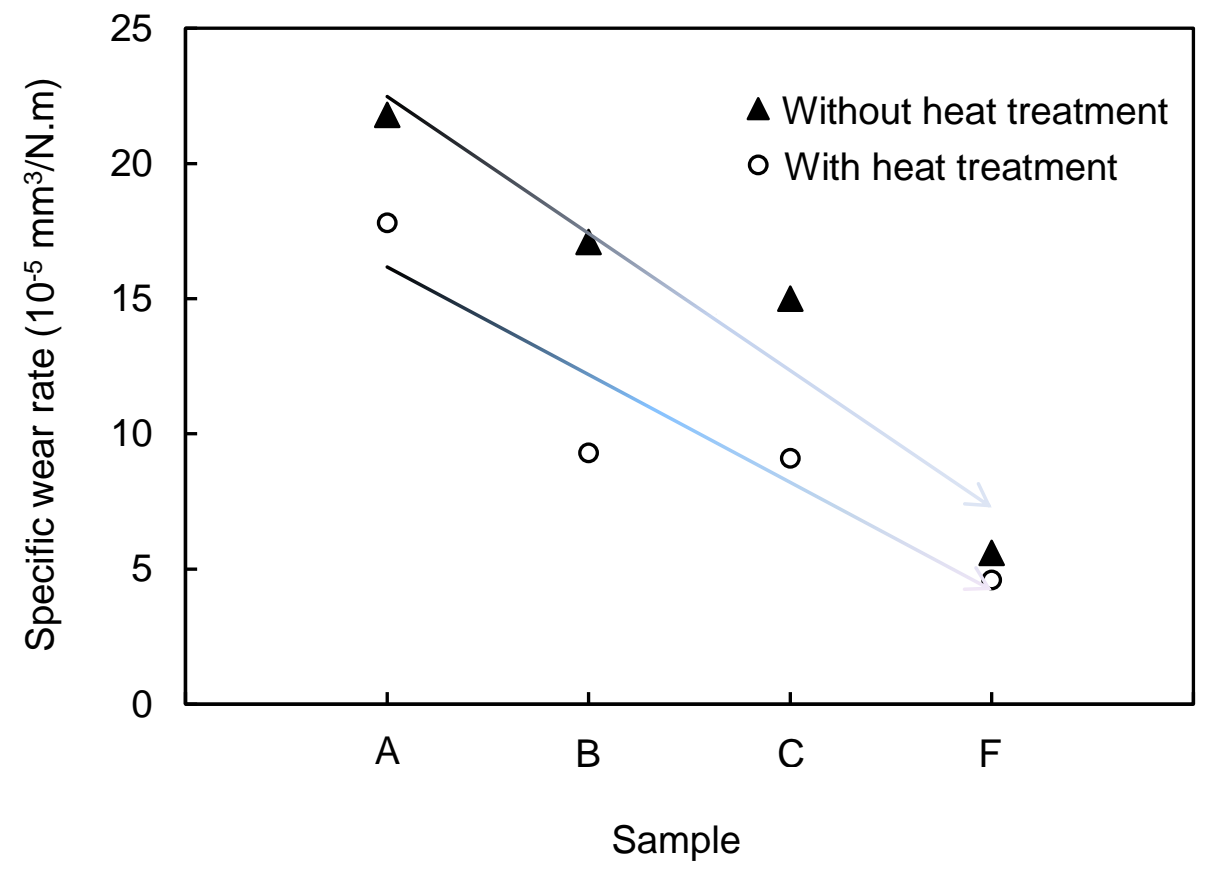

Fig. 4 

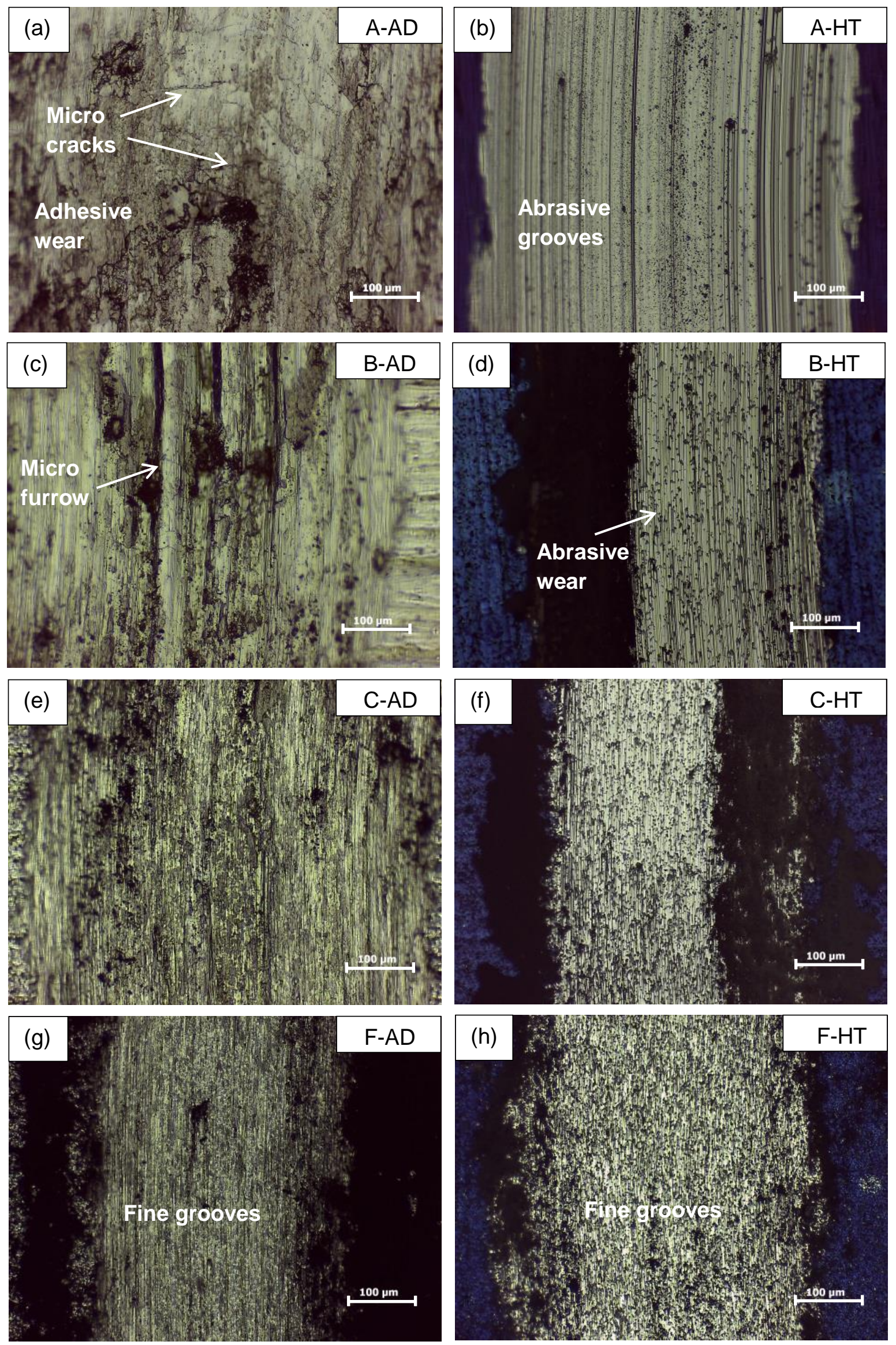

Fig. 5 

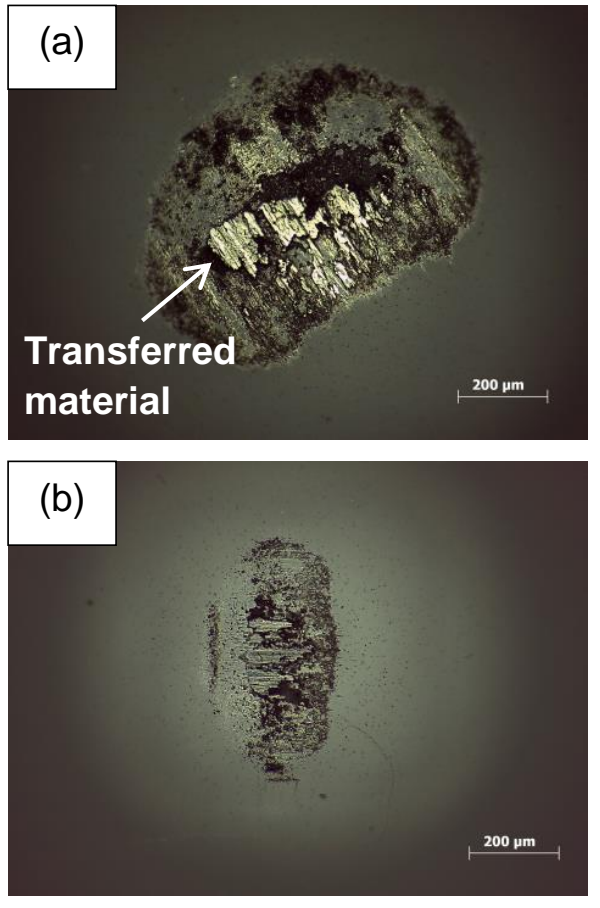

Fig. 6 

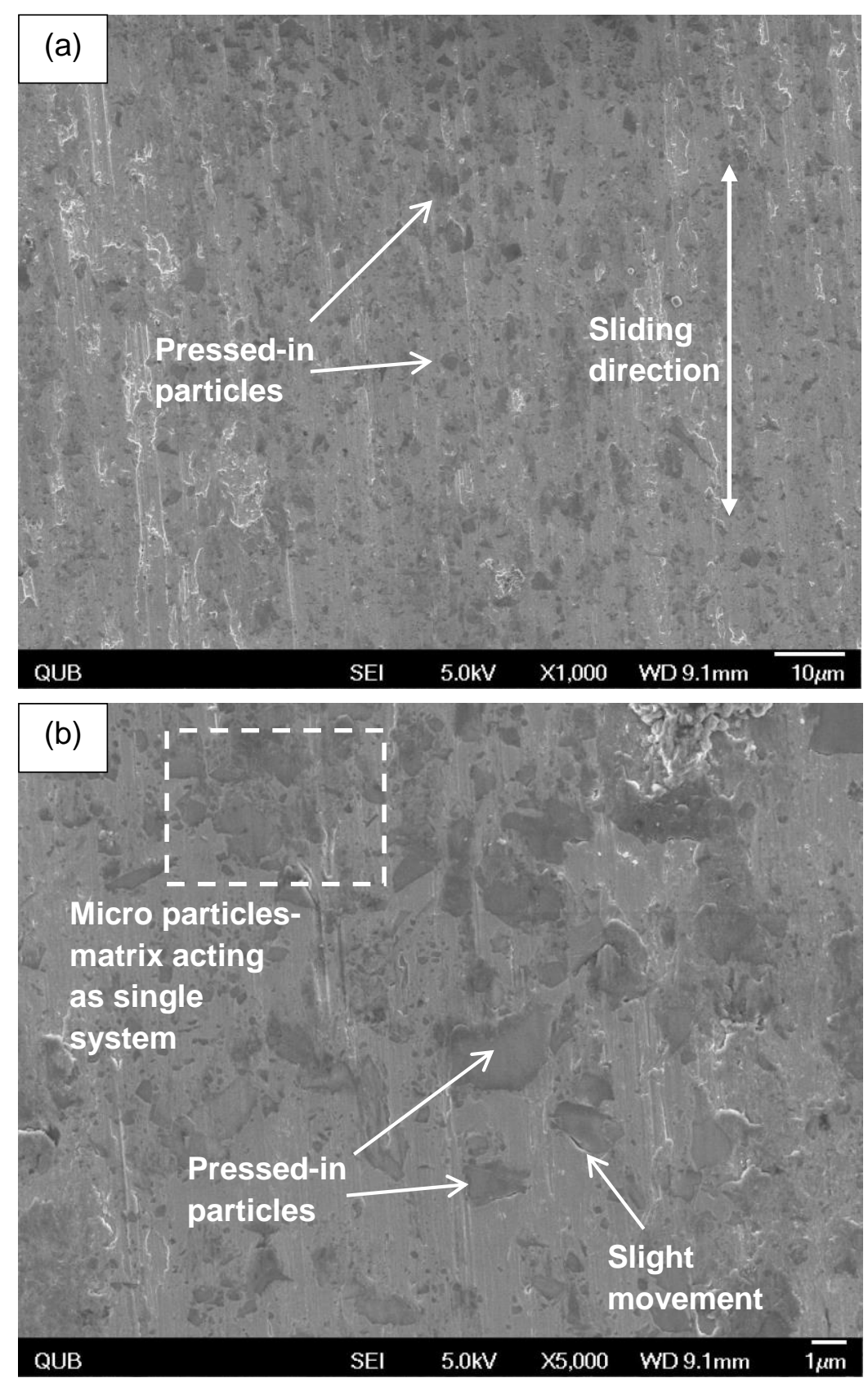

Fig. 7 

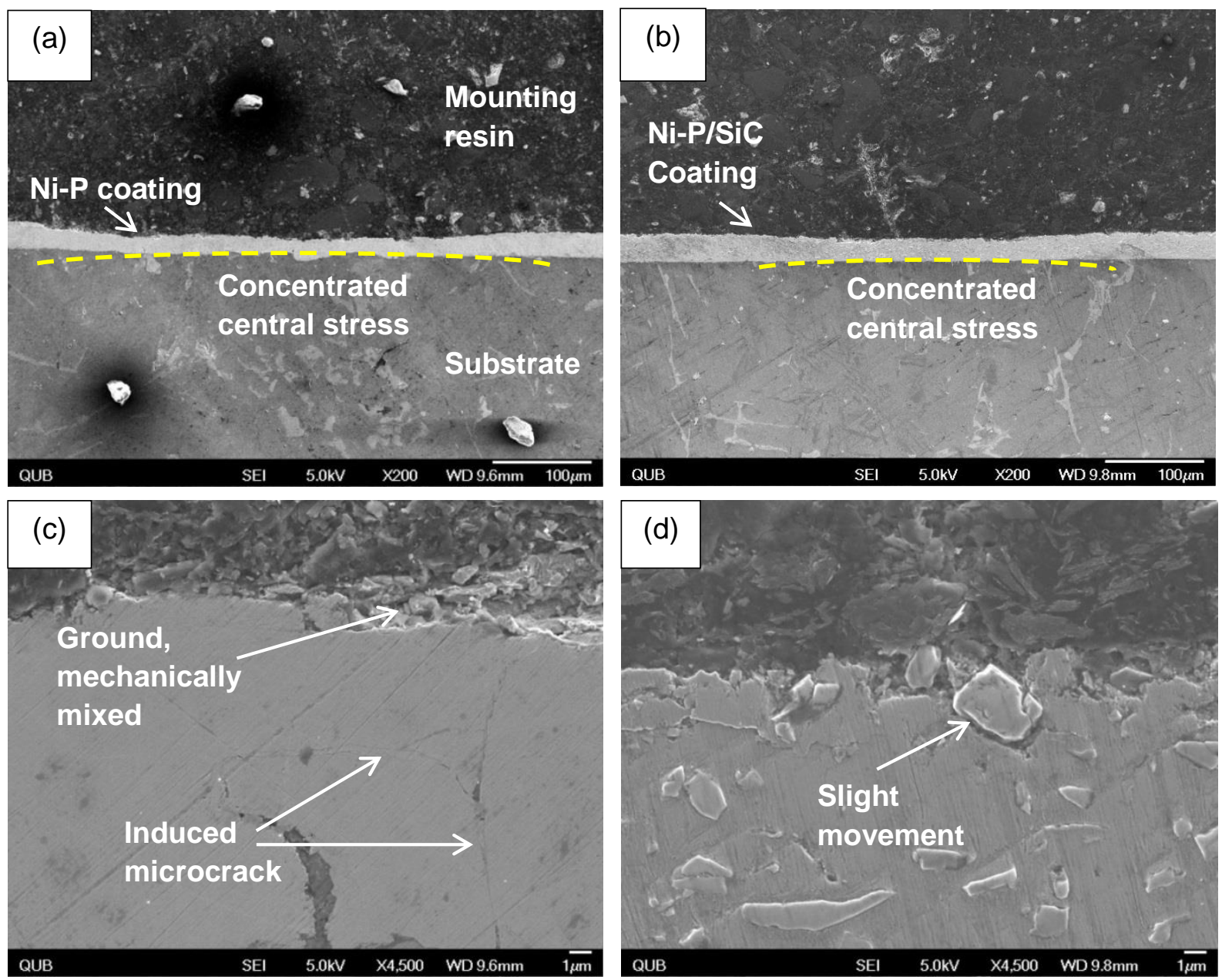

Fig. 8 

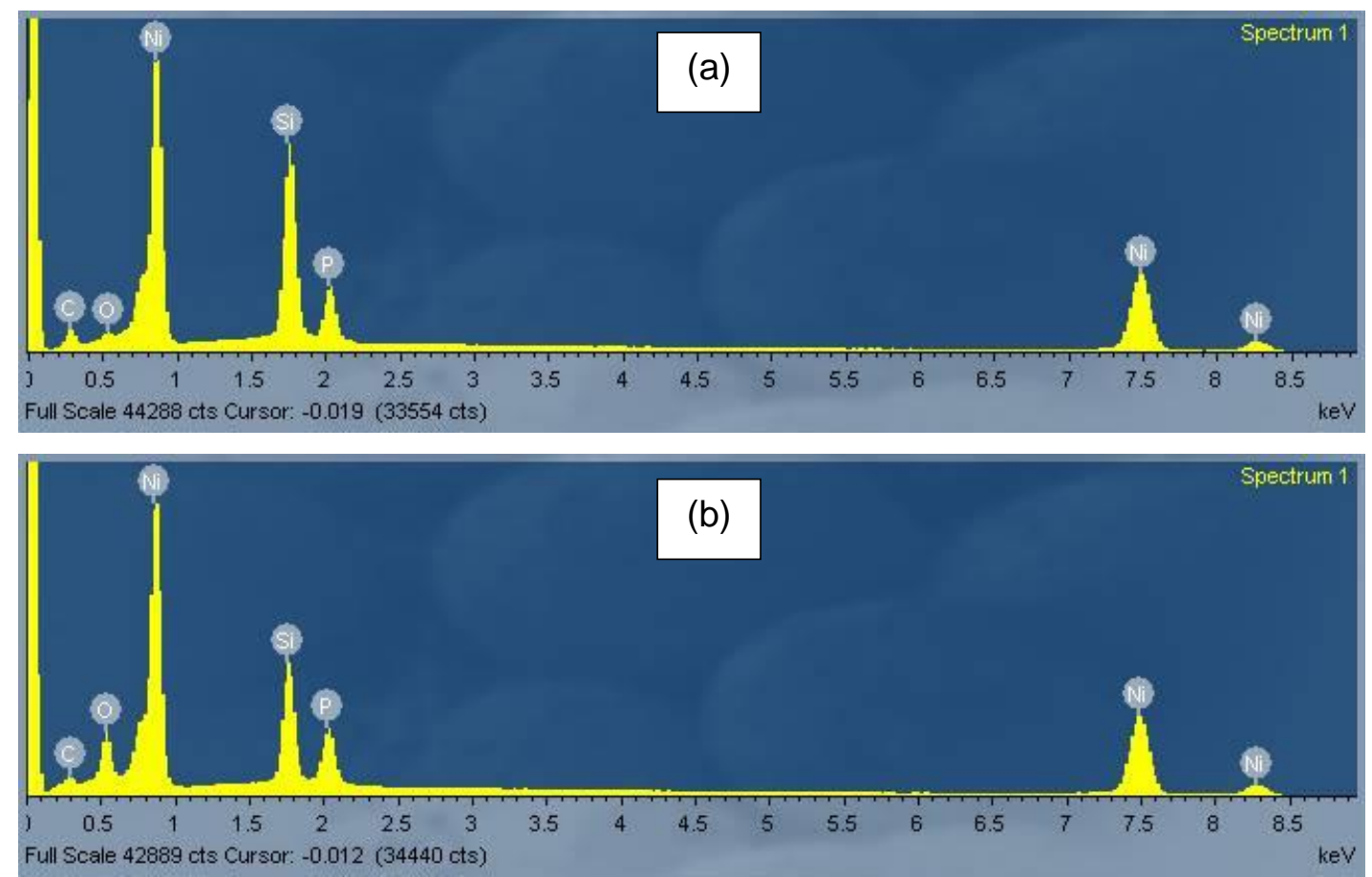

Fig. 9 


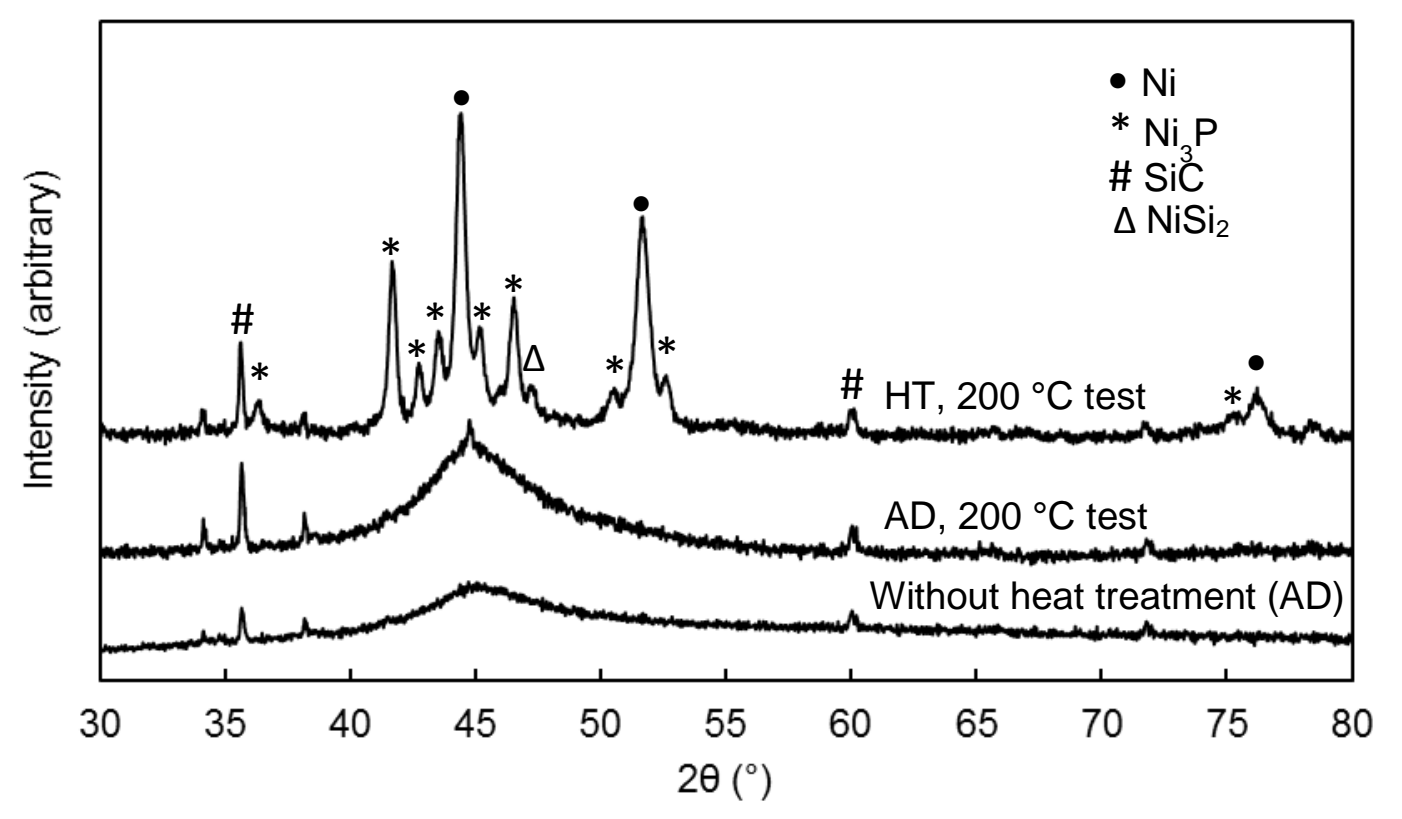

Fig. 10 